\title{
Mortality in fishermen: an unusual age distribution
}

\author{
C I Neutel
}

\begin{abstract}
Age specific standardised mortality ratios (ASMRs) were compared for commercial fishermen under 55 years old and those who were aged 55 and older in the Canadian Atlantic coastal provinces of Nova Scotia, New Brunswick, and Prince Edward Island. The subjects were a cohort of 31415 fishermen licensed by the Department of Fisheries and Oceans during 1975-83. Mortality was obtained by a computerised linking of the registry of licensed commercial fisheries and the Canadian Mortality Data Base. Fishermen under 55 had ASMRs between 1.4 and 1.7 for death from all causes and around 1.0 for death from non-accidental causes. The older fishermen had ASMRs as low as 0.6 for all causes and nonaccidental causes. The same pattern was shown for death from specific causes such as ischaemic heart disease, accidents, and cancer, as well as for different years of entry into the cohort. This pattern differed widely from that of most other occupations. Dividing the cohort into owners and crew members showed that the high mortality ratios at younger ages existed in crew members only. It was concluded that the high death rates for fishermen under 55 had a socioeconomic component.
\end{abstract}

Relatively little is known about the morbidity and mortality of commercial fishermen, particularly Canadians. Previous investigators found increases in cancer of the stomach and nose, ${ }^{1}$ lip, ${ }^{2}$ and lung. ${ }^{3-6}$ High accident rates have been reported for fishermen in Canada ${ }^{7}$ and elsewhere ${ }^{8-10}$ suggesting that fishing is a hazardous occupation.

A cohort of commercial fishermen registered in three provinces of the Canadian east coast (Nova Scotia, New Brunswick, and Prince Edward Island) was shown to have an unusually high mortality in fishermen under 55 years of age. ${ }^{7}$ The objective of the present paper was to evaluate this finding and, if possible, to establish an explanation.

Food Directorate, Health Protection Branch, Health and Welfare Canada, Ottawa, Ontario K1A 0L2, Canada

C I Neutel
Methods

The Department of Fisheries and Oceans made $\overrightarrow{\vec{H}}$ available the fishermen registry for the three provin- $\omega$ ces and included all persons who applied for a $\bigcirc$ commercial fishing licence between 1975 and 1983. Canadian law requires each person engaged in $A$ "limited entry" fishing (fishing for which maximum io quantities a season have been set-for example, on lobster, groundfish, mackerel, and herring) to obtain $\infty$ an annual commercial licence. Around 3\% of the $\frac{\text { o }}{2}$ population who registered for a fishing licence were women but as the population size was insufficient for separate analysis they were not included in the study.

Since 1975 (except for 1976) the registry data have $\stackrel{\oplus}{\rightarrow}$ been in machine readable form and thus it was $\vec{\oplus}$ possible to link these data to the Canada Mortality Data Base. The linkage process produced a total of 1289 male deaths. The 31415 fishermen accumulated 183378 person-years during 1975-83. Once a fisherman was registered as a commercial fisherman he stayed in the study until 1983 or death; whichever occurred first.

The analysis consisted of calculating standardised $\overrightarrow{\vec{O}}$ mortality ratios (SMRs) and age specific standardised mortality ratios (ASMRs) for subgroups of the population. The expected number of deaths for each subgroup was calculated by using the Canadian death $\odot$ rates or the death rates for the Canadian Maritime $?$ provinces, Nova Scotia, New Brunswick, and Prince $\frac{5}{3}$ Edward Island. The variance for the rates was calculated by using the formula $\mathrm{O} / \mathrm{E}^{2}$ where $\mathrm{O}$ is the $O$ observed numbers of deaths and $\mathrm{E}$ the expected number. ${ }^{11}$

\section{Results}

Figure 1 shows the age distribution of the fishermen $\bar{N}$ in this cohort. Most fishermen were between 20 and ${ }^{\circ}$ 50 . The large number of fishermen at the older age $N$ ranges is unusual for an occupational population. N Over 2000 men above the age of 70 and even some ing their 80 s and 90 s were licensed to fish.

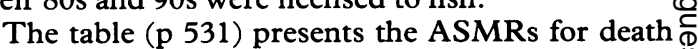
from all causes, as well as for selected specific causes $\stackrel{\oplus}{+}$ of death classified according to the International 7 Classification of Diseases. ${ }^{12}$ The all cause SMR was $\stackrel{9}{9}$ 0.80 using the Canadian national death rates and $0.78 \stackrel{\mathbb{\Omega}}{\Omega}$ using the death rates for the Maritime provinces. $\stackrel{\mathbb{Q}}{\mathbb{Q}}$ Water transport accidents and drowning (E830-8, 0 E910) are the only category showing a substantial difference with SMRs of 8.41 or 5.31 . For the 
remainder of this article expected numbers are calculated using the maritime death rates.

Figure 2 shows the ASMRs for death from all causes by ten year age groups. Fishermen under 45 showed high mortality ratios, with a rapid fall for older ages. The confidence limits suggest that the trend in the curve is not erratic but that the high part differs significantly from the low part.

Figure 3 compares the ASMRs for mortality from all causes with the mortality due to all causes less accidents. Although the initial peak was greatly reduced the pattern stayed the same-an initial high followed by a rapid fall resulting in a plateau at a lower than expected level. Since only four nonaccidental deaths occurred in the 15-24 age group this group was combined with the next older group. The broken line, labelled "other occupations" shows a curve that is more typical of occupational cohorts. ${ }^{13}$

Figure 4 shows that patterns for mortality due to heart disease, respiratory diseases, and cancer were similar to those for mortality from all causes in the cohort of fishermen.

Figure 5 compares those fishermen who registered in 1975 with those who did not enter the study until 1978 or later. The year 1975 was the first year for which the licence data were available for the study but many of the fishermen who registered then had been fishing for many years. Those that first entered the study in 1978 may have been new fishermen or have fished before 1975. The two curves are similar.

Figure 6 presents the mortality experience of those fishermen who were owners of a vessel $v$ non-owners (mostly crew). Unfortunately this information was available for 1978-83 only. At the younger age groups, mortality of owners was much lower than that for crew. At the older age groups owners and crews had similar mortality ratios; this was the case for all causes of death and non-accidental causes. Because of small numbers for owners the age groups 35-44 and 45-54 have been combined. Figure 7 shows the contributions of person-years by crew and owners for different age groups.

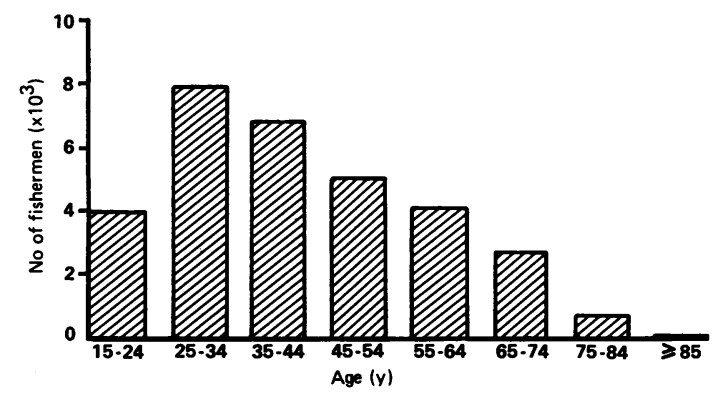

Figure 1 Numbers of licensed fishermen in Nova Scotia, New Brunswick, and Prince Edward Island (Scotia Fundy region) $1975-83$.

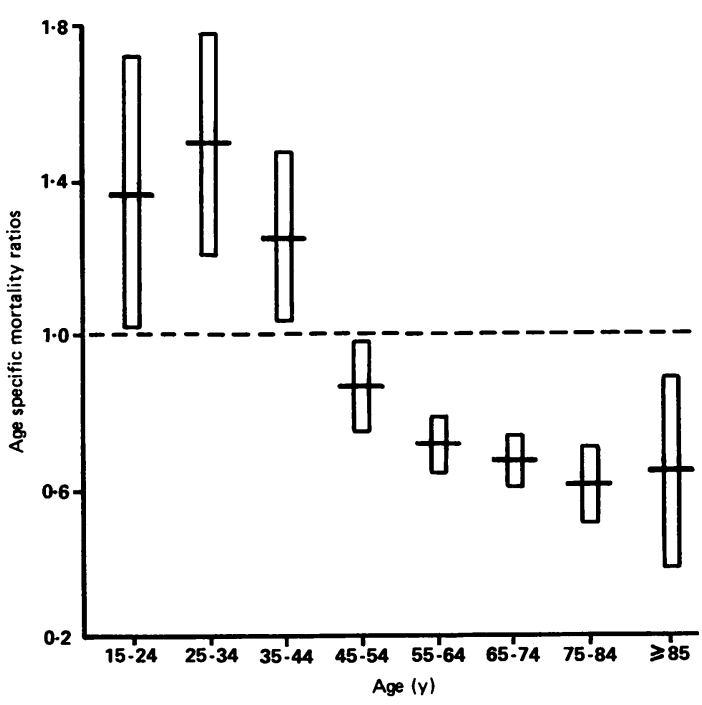

Figure $2 A S M R$ values for all causes among fishermen.

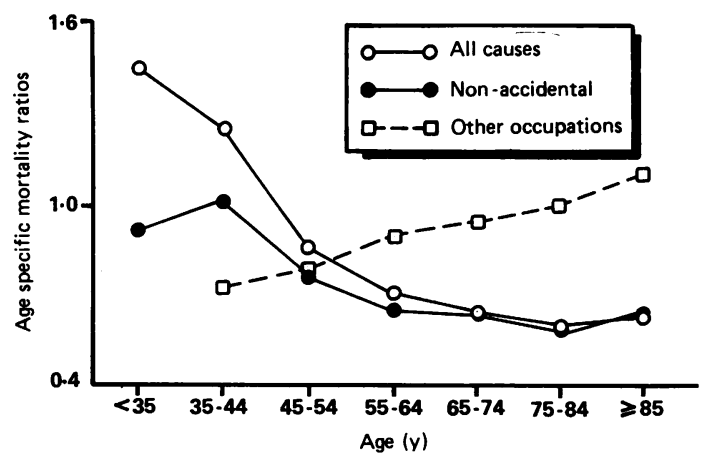

Figure 3 ASMR values for all causes and non-accidental causes among licensed fishermen.

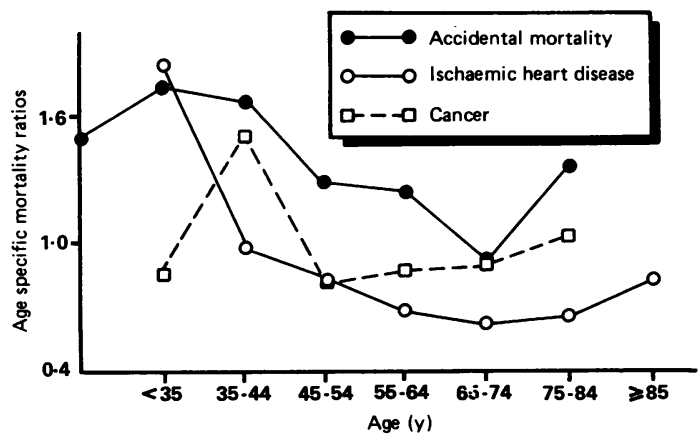

Figure 4 ASMR values for cancer, heart disease, and accidental causes among licenced fishermen. 


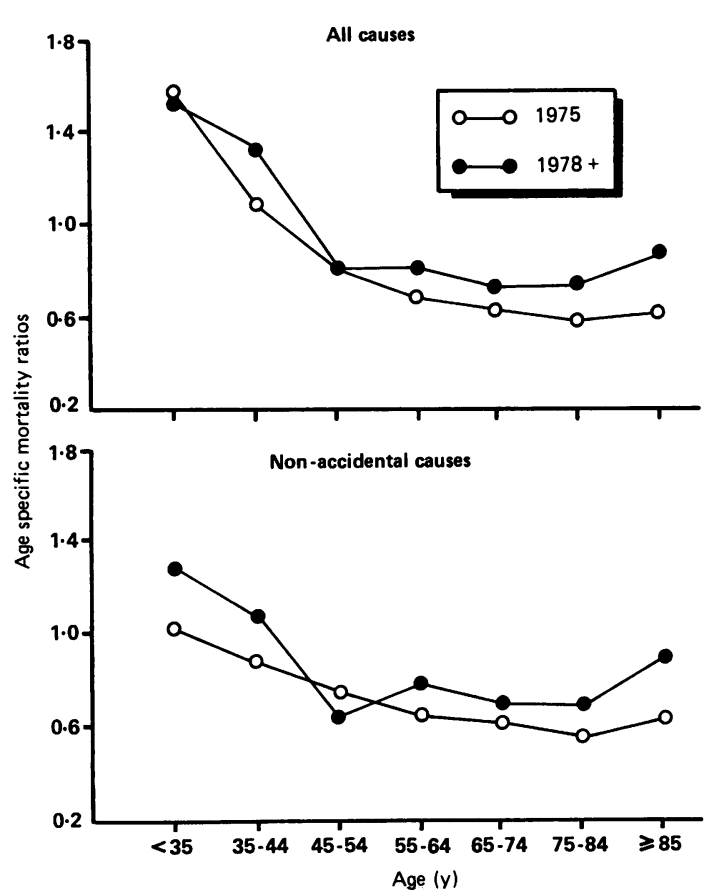

Figure 5 ASMR values for fishermen first licensed in 1975 or 1978 and later.

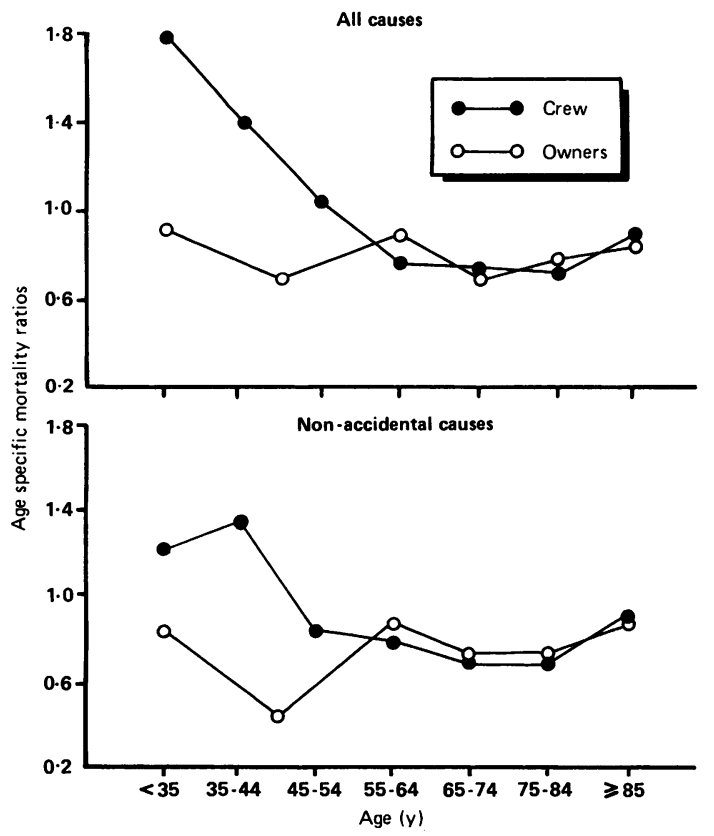

Figure 6 ASMR values for licensed fishermen owners or crew.

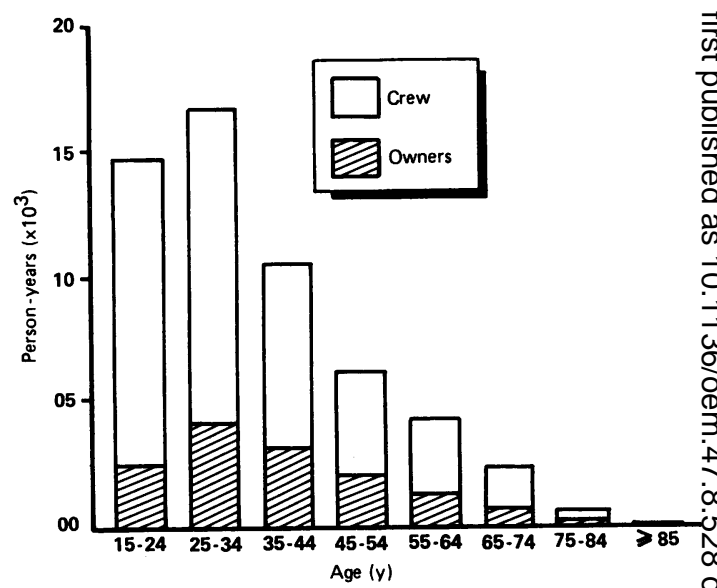

Figure 7 Person-years for licensed fishermen (owners or crew) $1975-83$.

\section{Discussion}

Over the years researchers have amassed a large $\vec{\varrho}$ amount of data on occupations and have noted thaP there are certain common features. ${ }^{13-17}$ The mosf prominent of these affecting mortality and morbiditys is the healthy worker effect; the phenomenor whereby employed individuals tend to have lowe death rates than those who are unemployed..$^{15}$ Thi $\$_{0}$ was documented in a review of 50 occupational studies, of which $80 \%$ had an SMR of less than one. Thus the SMR of 0.78 for fishermen (table) was expected based on other studies. The low SMR for occupational groups in general is not surprising as an employee needs a certain level of health to hold a job and he or she is likely to leave employment if health deteriorates. The magnitude of the healthy workes effect is influenced by the structure of the study which determines the relative influence of two maing types of selection forces.

Selection on entering the workforce-New entrants in? an occupational study may be restricted to new employees entering an industry after a chosen date, or may include all those employed at that date. It is obvious that the two methods would produce quite $\mathrm{h}$ different study population, if only in age distribu 고 tion. For the cohort of fishermen the earliest entrants $s^{\omega}$ were those obtaining a commercial fishing licence in 1975, many of whom had been fishing for severaf years; in that sense it was similar to including al existing employees. Unfortunately registration was not complete in the early stages and it is difficult to know whether those registering were representative of all commercial fishermen at the time. The Depart $\frac{?}{D}$ ment of Fisheries and Oceans claims that a few years later the registration became and remained close to $100 \%$. As commercial fishing is known to be af physically demanding occupation those registering 
may be expected on average to be stronger and healthier than the general population.

Selection governing those who remain in the study-In some occupational studies individuals are in the study only as long as they are on the books of their employer and are lost when they retire or change jobs due to health state or for other reasons. In this study all those who registered after 1974 remained in the study whether or not they registered again and the only reason for removal from the population was death. This study is short term, however, compared with many other occupational studies that cover decades. In a relatively long term study a typical ASMR curve approaches one at retirement age (see fig 3). It was hypothesised that those fishermen who registered in 1975, most of whom would have fished for many years, would show a more typical curve than those who did not register for the first time until 1978 or later. This expectation was not borne out (fig 5). A possible reason for the lack of difference between the two curves could be that some of those who apparently registered for the first time in 1978 had been long term fishermen but had not registered in 1975 or 1977.

The choice of a reference population will influence the healthy worker effect as well as the magnitude of the SMR. For the purpose of this study it seemed preferable to deal with a known, albeit relatively large difference, such as that resulting from using a national population, rather than with a comparison group, which may show little or no healthy worker effect-for example, another occupational groupbut may in fact hide an inherent difference. For this reason mortality of the fishermen was compared with mortality of the general population (inherent in the calculation of ASMR) rather than that of another occupational group.

The table compares SMRs based on both the Canadian rates and rates for the Maritime provinces. For non-accidental causes the results are similar but slightly lower using rates for the Maritime provinces, a difference of less than $0 \cdot 05$. For the special cases of water transport accidents and drowning, the SMR using Canadian rates was 8.41 and 5.31 using rates for the Maritime provinces. The fishermen were a sufficiently large portion of the population of the Maritime provinces that their presence as part of the denominator lowered the SMR for water transport accidents somewhat (subtracting the population of fishermen from the population of the Maritime provinces in both numerator and denominator and recalculating the rates produced an SMR of 6.08). Regardless of referent population these water transport accident statistics are underestimates as fishermen who drowned and whose bodies were not recovered received no death certificates and would not be included in this study. This problem is discussed in detail elswhere ${ }^{18}$ (and P Hasselback, C I Neutel, Canadian conference on epidemiological research, Ottawa, 1989).

Figures 2 and 3 illustrate a unique aspect of the mortality of fishermen; whereas other occupations show the lowest ASMR in younger age groups, the fishermen start out with a high ratio, which drops sharply between the ages of 45 and 55 and ends with unusually low ratios for fishermen older than 55 . At this age mortalities for other occupations tend to increase and approach that of the general population. The low mortality ratios for the older fishermen are not, however, surprising. These individuals are known to be active workers as they registered at least once and usually more than once during the eight years of the study. As more individuals drop out of a cohort (in this study before 1975 only) because of poor health with increasing age, those that remain become a smaller proportion of the population and their health experience is relatively better. Thus this may be considered an extreme form of healthy worker effect in a population where no mandatory retirement age exists.

The reason for the high mortality of the younger men is more difficult to explain. It is unusual for men actually working to have a higher mortality than the general population as expressed by an ASMR greater

Table SMRs for various causes of death among fishermen

\begin{tabular}{|c|c|c|c|}
\hline Cause of death & Observed & SMR† & SMR‡ \\
\hline $\begin{array}{l}\text { All causes } \\
\text { All causes less accidents } \\
\text { Cancer: all sites (ICD 140-208) } \\
\text { Ischaemic heart disease (ICD 410-4) } \\
\text { Respiratory disease (ICD 460-519) } \\
\text { Cerebrovascular disease (ICD 430-8) } \\
\text { Accidents and violence (ICD E800-999) } \\
\text { Motor vehicle accidents (ICD E810-25, 929) } \\
\text { Suicide (ICD E950-9) } \\
\text { Water transport accidents and drowning (ICD E830-8, E910) }\end{array}$ & $\begin{array}{r}1289 \\
990 \\
399 \\
407 \\
38 \\
62 \\
299 \\
103 \\
48 \\
95\end{array}$ & $\begin{array}{l}0.80 \\
0.70 \\
0.92 \\
0.71 \\
0.39 \\
0.67 \\
1.53 \\
1.60^{\star} \\
0.92 \\
8.41^{\star \star}\end{array}$ & $\begin{array}{l}0 \cdot 78 \\
0 \cdot 69 \\
0.90 \\
0 \cdot 71 \\
0 \cdot 34 \\
0 \cdot 72 \\
1 \cdot 45^{\star} \\
1 \cdot 40^{\star} \\
0 \cdot 92 \\
5 \cdot 31^{\star}\end{array}$ \\
\hline
\end{tabular}

${ }^{\star} \mathrm{p}<0.05 ;{ }^{\star \star} \mathrm{p}<0.01$.

+SMR calculated using Canada national death rates.

ISMR calculated using death rates for the Maritime provinces.

ICD $=$ International Classification of Diseases. ${ }^{12}$ 
than one. A high ASMR for the under $\mathbf{4 5}$ group was found not only for mortality from all causes but also for accidents, heart disease, and respiratory disease. The high mortality across the various causes may indicate a subpopulation living under generally adverse conditions.

Personal communication from $M$ Binkley of the Department of Anthropology and Sociology, Dalhousie University, and discussions with officials of the Department of Fisheries and Oceans in Halifax, indicated that many fishermen, especially trawlermen, deckhands, and learners, often lead an excessively stressful life. According to Binkley's research the fishermen can be divided into two socioeconomic groups.

Firstly, the boat owners, captains, and officers, who are dedicated men; many have specialised training and certificates. These people often have a reasonable income and a feeling of control over their lives. They are professionals and tend to stay fishermen for life.

Secondly, the crew, trawlermen, deckhands, and learners, who are poorly educated and have often gone to sea rather than finish high school. They have little or no chance of advancement in their work. The general feeling among them appears to be that they would not continue fishing after the age of 45 if at all possible.

The present study supports the idea of two distinct groups of fishermen. Information from the vessel registration application was used as evidence that a fisherman owned a boat and this was used as an indicator for social class. The owners of small boats were likely to be inshore fishermen who go out on a daily basis; this allows a regular family and community orientated life style. Trawlers may range from less than 35 feet to those up to 65 feet long and the owner may be the captain or remain ashore. The nonowners were the crew (assistants, deckhands, icers), many of whom would work on trawlers that may have crews of 10 or more. Figure 6 shows the difference in mortality from all causes for owners and non-owners or crew who registered in 1978 or later (regardless of whether they registered earlier or not) as the information was not available on the data for earlier years. The graph shows a divergence of ASMR at the younger age groups; the ASMRs then approached each other after the age of 50 . Thus divergence for the younger age group could be due to socioeconomic differences. Figure 7 shows the age distribution of person-years contributed by the owners and the crew. The crew contributed a much larger proportion of person-years for the younger age groups; thus the mortality for the total group of fishermen reflects the high mortality of the crew. At older ages the porportion of crew was not as great.

Further investigation is needed to determine whether the high mortality at the early ages is due to the extreme, physically stressful working conditions and accompanying lifestyle, or whether there are other reasons. The possibility that commercial fishing attracts individuals who are already unhealthyo seems unlikely given the demanding nature of the work. If it should be confirmed that the high $\frac{\bar{s}}{\supset}$ mortality is due to working conditions, or personal or $\stackrel{\mathbb{D}}{\Omega}$ community life style, then further studies need to be carried out to analyse these and to find ways todecrease the mortality.

I acknowledge the help of the Occupational and Environmental Health Research Section of Statistics $\mathbb{D}$ Canada in the record linkage procedure; the Health 3 Division of Statistics Canada and the registrars of the $\vec{A}$ provinces for the use of the Canada Mortality Dataio Base; the Department of Fisheries and Oceans for then use of their computerised registry; Dr M Binkley for her advice and insight; Dr L Bradshaw and the Food ${ }^{\circ}$ Directorate, Health Protection Branch, Health and Welfare for making this study possible; $P$ Hasselback for helpful comments; P Laffey for statistical advice; and $\mathrm{L}$ Touckley for programming.

1 Gallagher RP, Threlfall WJ, Band PR, Spinelli JJ. Cancere mortality experience of woodworkers, loggers, fishermen, farmers and miners in British Columbia. National Cancer Institute Monograph 1985;69:163-7.

2 Spitzer WO, Hill GB, Chambers LW, Helliwell BE, Murphy HB. The occupation of fishing as a risk factor in cancer of the lip. N Engl J Med 1975;293:419-24.

3 Dubrow R, Wegman DH. Cancer and occupation in Massa-0 chusetts: a death certificate study. Am J Ind Med 1984;6. 207-30.

4 Gottlieb MS, Pickle LW, Blot WJ, Fraumeni JF. Lung cancer in $\overrightarrow{\overrightarrow{5}}$ Louisiana: death certificate analysis. JNCI 1979;63:1131-7.

5 Gottlieb MS, Carr JK. Mortality studies on lung, pancreas, esophageal and other cancers in Louisiana. Banbury Repor 1981;9:195-204.

6 Frazier TM, Wegman DH. Exploring the use of death certificates as a component of an occupational health surveillance system. Am J Public Health 1979;69:718-20.

7 Neutel CI. Mortality in commercial fishermen of Atlantic Canada. Can J Public Health 1989;80:375-9.

8 Schilling RSF. Trawler fishing: an extreme occupation Proceedings of the Royal Society of Medicine 1966;59:405-10.

9 Cadenhead R. Hospital admissions of fishermen from the fishing grounds around the Shetland Islands. J Soc Occup Med 1976;26:127-31.

10 Reilly MSJ. Mortality from occupational accidents to United Kingdom fishermen 1961-80. $\mathrm{Br} J$ Ind $\mathrm{Med}$ 1985;42. 806-14.

11 Breslow NE, Day NE. Statistical methods in cancer research Vol II. The design and analysis of cohort studies. LyonN International Agency for Research on Cancer, 1987:62.

12 International Classification of Disease. Manual of the inter national classification of diseases, injuries and causes of death. 9 tho version. Geneva: World Health Organisation, 1977.

13 McMichael AJ. Standardized mortality ratios and the "healthy $\omega$ worker effect": scratching beneath the surface. J Occup Med 1976;18:165-8.

14 Waxweiler RJ, Haring MK, Leffingwell SS, Halperin w Quantification of differences between proportionate mortality ${ }_{\mathbb{S}}$ ratios and standardized mortality ratios. Banbury Report? $1981 ; 9: 379-87$

15 Walter SD. Cause-deleted proportional mortality analysis and the healthy worker effect. Stat Med 1986;5:61-71.

16 Tsai SP, Wen CP. A review of methodological issues of the standardized mortality ratio (SMR) in occupational cohort studies. Int J Epidemiol 1986;15:8-21. 17 Monson RR. Observations on the healthy worker effect. J Occup
Med 1986;28:425-33.

18 Hasselback P, Neutel CI. Risk for commercial fishing deaths in Canadian Atlantic Provinces. Br J Ind Med 1990:47:498-501 응

Accepted 22 January 1990. 